\title{
ANALISIS KEUNTUNGAN USAHA CV. INDOSPICE DI TUMINTING KOTA MANADO
}

\author{
Tri Mirta Dewi \\ Paulus A. Pangemanan \\ Ribka M. Kumaat
}

\begin{abstract}
This study aims to analysis the profit received by $\mathrm{CV}$. Indospice in one month production process. The study was conducted in January to March 2017. Located at CV. Indospice in Tuminting, Manado City. This research uses primary data and secondary data. The data used in this study using tables that are then described and analysis using profit analysis. The profit was obtained by the difference between revenue and cost incurred. The results showed that $C V$. Indospice in Tuminting, Manado City get a profit of Rp. 153,618,396 per month at a cost of Rp. 748.381 .604 and the value of $R / C$ cost revenue of 1.29 which means $C V$. Indospice gained profit.*jnkd*.
\end{abstract}

Keywords: profit analysis, CV. Indospice, Tuminting, Manado City

\begin{abstract}
ABSTRAK
Penelitian ini bertujuan untuk menganalisis keuntungan yang diterima oleh CV. Indospice dalam satu bulan proses produksi. Penelitian ini dilakukan dari bulan Januari sampai Maret 2018. Berlokasi di pabrik pala pada CV. Indospice di Tuminting Kota Manado Penelitian ini menggunakan data primer dan data sekunder. Data yang dikumpulkan dalam penelitian ini disajikan dalam bentuk tabel kemudian di deskripsikan dan dianalisis dengan menggunakan analisis keuntungan. Keuntungan diperoleh dari selisih antara penerimaan dan biaya yang dikeluarkan. Hasil penelitian menunjukan bahwa CV. Indospice di Tuminting Kota Manado ini mendapatkan keuntungan sebesar Rp. 153.618.396 per bulan dengan biaya sebesar Rp. 748.381.604 dan nilai R/C cost revenue sebesar 1,29 yang artinya $\mathrm{CV}$. Indospice memperoleh keuntungan. *jnkd*
\end{abstract}

Kata kunci: analisis keuntungan, CV. Indospice, Tuminting, Kota Manado

\section{PENDAHULUAN}

\section{Latar Belakang}

Pertanian merupakan sektor primer dalam suatu perekonomian, pengembangan dan pembangunannya yang dilakukan secara matang sejalan dengan pengembangan sektor industri dan jasa yang menjadi pendukung sehingga tidak terjadi kepincangan dalam perekonomian. Pengamatan empiris menunjukkan landasan menuju pembangunan ekonomi berkelanjutan yang digerakan oleh sektor industri dan jasa setelah didahului oleh kemajuan disektor pertanian. (Priyarsono, 2005). Pembangunan pertanian diarahkan untuk meningkatkan produksi pertanian, untuk kebutuhan pangan, kebutuhan industri, serta meningkatkan ekspor dan pendapatan dan untuk mendorong pemerataan kesempatan berusaha. (Soekartawi, 2003).

Sektor pertanian di Indonesia masih memiliki banyak peluang dan mempunyai prospek yang cerah namun belum digali secara maksimal. Pada masa sekarang sektor industri lebih diutamakan dan perkembangan sektor pertanian tidak lepas sebagai pendukung yang kokoh, maka harus ada kerja sama antar bidangbidang yang berkaitan. 
Sulawesi Utara mempunyai berbagai sumberdaya alam yang sangat potensial untuk pengembangan komoditi pertanian, salah satunya yaitu pala (Mysristic fragans houtt). Tanaman pala merupakan tanaman rempahrempah asli rakyat Maluku dan telah diperdagangkan dan dibudidayakan secara turun temurun dalam bentuk perkebunan rakyat di sebagian besar Kepulauan Maluku. Pala Indonesia memiliki nilai tinggi di pasar dunia karena aromanya yang khas. Buah ini dikenal sebagai tanaman rempah yang memiliki nilai ekonomis dan multiguna.

Agroindustri merupakan salah satu bentuk industri yang menggunakan bahan baku pertanian. Sehingga agroindustri dapat menjadi salah satu pilihan strategis dalam menghadapi masalah untuk meningkatkan perekonomian masyarakat. Sektor industri pertanian yang biasa disebut agroindustri merupakan suatu sistem pengelolaan secara terpadu antara sektor pertanian dengan sektor industri guna mendapatkan nilai tambah dari hasil produk pertanian tersebut.

Usaha agroindustri menjadi penting untuk dikembangkan karena sumberdaya alam yang melimpah dan perlu dikelolah dengan baik agar dapat menghasilkan nilai ekonomis, pengelolaan sumberdaya alam melalui usaha agroidustri ini dilakukan oleh salah satu pabrik pengolahan biji pala di Kota Manado.

CV. Indospice adalah salah satu agroindustri yang mengembangkan industri dengan menggunakan bahan baku pala terutama biji pala. Berbagai tantangan yang ditemui dalam usaha ini, salah satunya adalah kenaikan harga pala akibat kelangkaan biji pala yang banyak diperlukan.CV. Indospice dihadapkan dengan tantangan-tantangan tersebut tapi tetap bertahan hingga sekarang, sehingga perlu di analisis berapa keuntungan dari CV. Indospice karena tujuan dari setiap usaha yang didirikan pada umumnya adalah untuk memperoleh keuntungan yang semaksimal mungkin.

\section{Deskripsi Tanaman Pala (Myristica fragnans Houtt)}

Tanaman Pala (Myristica fragrans Houtt) merupakan tanaman asli Indonesia, yang sudah dikenal sebagai tanaman rempah sejak abad ke18. Sampai saat ini Indonesia merupakan produsen pala terbesar di dunia (70-75\%). (Agus dan Martini, 2015).

\section{Konsep Agroindustri}

Agroindustri berasal dari dua kata yaitu agricultural dan industry yang berarti suatu industri yang menggunakan hasil komoditi pertanian sebagai bahan baku utamanya (Kusnadar, 2010).

\section{Persediaan Bahan Baku}

Persediaan bahan baku merupakan aktiva perusahaan yang digunakan untuk proses produksi didalam suatu perusahaan dan disediakan untuk memenuhi kebutuhan dan keinginan pelanggan setiap waktu (T. Hani Handoko, 2000).

\section{Konsep Biaya}

Menurut Supriyono (2000) biaya adalah harga perolehan yang digunakan dalam memperoleh penghasilan atau revenue yang akan dipakai sebagaipengurangan penghasilan.

\section{Konsep Produksi}

Produksi adalah menciptakan, menghasilkan dan membuat. (Sukirno, 2002). Adapun rumus matematisnya dapat ditulis sebagai berikut:

$$
\mathrm{TC}=\mathrm{FC}+\mathrm{VC}
$$

Keterangan:

TC $($ Total Cost $) \quad$ : Total Biaya

FC (Fix Cost) : Biaya Tetap

VC (Variabel Cost) : Biaya Variabel

\section{Konsep Harga}

Harga adalah variabel yang dapat dikendalikan dan dapat menentukan diterima tidaknya suatu produk oleh konsumen. Murah atau mahalnya harga suatu produk sangat relatif sifatnya (Anoraga, 2000).

\section{Penerimaan (Revenue)}

Penerimaan adalah jumlah nilai atau hasil penjualan yang diterima dalam menjalankan usaha. Menurut Soekartawi (1995), secara sistematis dapat ditulis:

Keterangan:

$$
\mathrm{TR}=\mathrm{Q} \times \mathrm{P}
$$

TR $($ Total Revenue $)=$ Penerimaan Total $(\mathrm{Rp})$

$\mathrm{Q}$ (Quantity)= Jumlah Produksi

$\mathrm{P}($ Price $) \quad=$ Harga dari hasil produksi $(\mathrm{Rp})$ 


\section{Pemasaran}

Kegiatan pemasaran merupakan faktor penting yang perlu diperhatikan oleh para pengusaha pala guna menjamin kelancaran penjualan produk. (Djoyodiporo, 2002).

\section{Keuntungan}

Keuntungan adalah selisih antara penerimaan total dan biaya-biaya (cost). Adapun rumus matematisnya dapat ditulis sebagai berikut:

$$
\begin{gathered}
\pi=T R-T C \\
\text { atau } \\
\pi=(Q \times P)-(F C+V C)
\end{gathered}
$$

Keterangan:

$\begin{array}{ll}\Pi(\text { Profit }) & =\text { Keuntungan } \\ \text { TR }(\text { Total Revenue }) & =\text { Penerimaan Total } \\ \text { TC }(\text { Total Cost }) & =\text { Total Biaya Produksi } \\ \mathrm{P}(\text { Price }) & =\text { Harga } \\ \mathrm{Q}(\text { Quantity }) & =\text { Jumlah Produksi } \\ \text { VC }(\text { Variabel Cost }) & =\text { Biaya Tetap } \\ \text { FC }(\text { Fixed Cost }) & =\text { Biaya Variabel }\end{array}$

\section{Konsep Analisis Revenue Cost $(\mathrm{R} / \mathrm{C})$}

Analisis Return Cost (R/C) ratio merupakan perbandingan (ratio atau nisbah) antara penerimaan dan biaya (Rahim A dan Hastuti DRD, 2008).

Dimana:

$$
\alpha=\mathrm{R} / \mathrm{C}
$$

$\mathrm{a}=$ Perbandingan antara penerimaan dan biaya

$\begin{array}{ll}\mathrm{R}(\text { Revenue }) & =\text { Penerimaan } \\ \mathrm{C}(\text { Cost }) & =\text { Biaya }\end{array}$

\section{Proses Produksi}

Untuk proses produksi dari biji pala tersebut dapat dijelaskan dalam diagram gambar 1 di bawah ini:

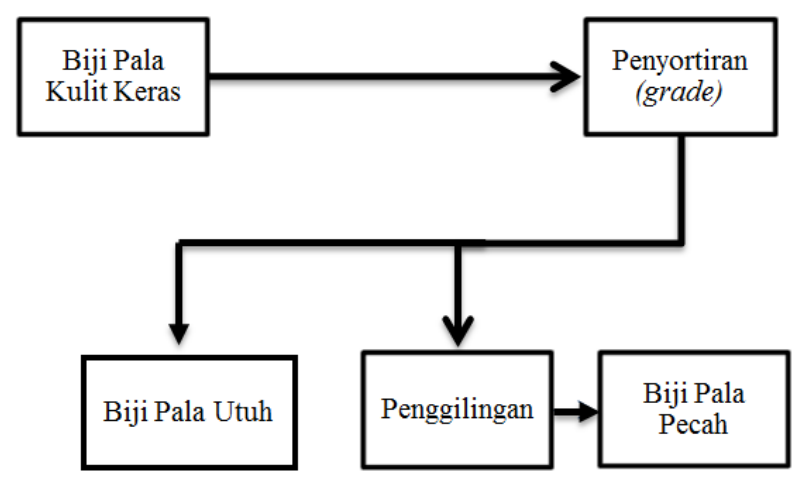

Diagram 1. Skema Proses Produksi

\section{Kerangka Berpikir}

Secara sistematis kerangka pemikiran dapat ditampilkan pada diagram gambar 2 dibawah ini:

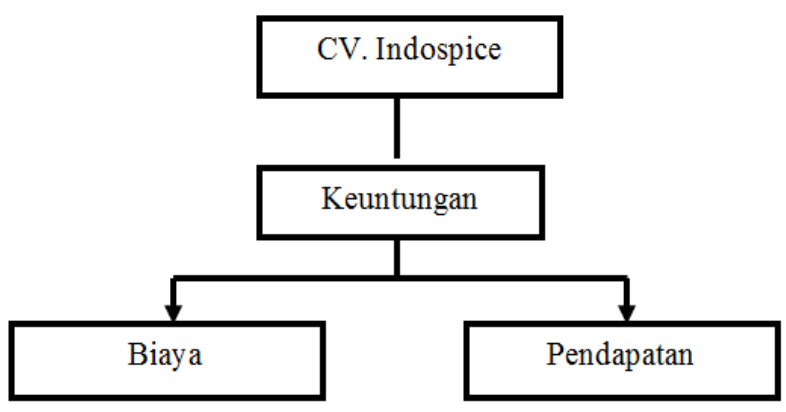

Diagram 2. Skema Kerangka Berpikir

\section{Rumusan Masalah}

Berdasarkan latar belakang yang telah diuraikan di atas maka rumusan masalah pada penelitian ini adalah berapa besar keuntungan usaha CV.Indospice di Tuminting Kota Manado dalam kurun satu bulan.

\section{Tujuan Penelitian}

Berdasarkan perumusan masalah yang telah dipaparkan di atas sehingga didapatkan tujuan penelitian ini adalah menganalisis keuntungan usaha CV. Indospice di Tuminting Kota Manado dalam kurun satu bulan.

\section{Manfaat Penelitian}

Manfaat dari penelitian ini adalah agar dapat memberikan informasi bagi pihak-pihak yang memerlukannya untuk menambah wawasan dan pengetahuan yang lebih luas mengenai agroindustri CV. Indospice serta diharapkan dapat digunakan sebagai bahan kajian untuk peningkatan usaha dalam rangka mencapai keuntungan yang maksimal.

\section{METODE PENELITIAN}

\section{Lokasi dan Waktu Penelitian}

Penelitian ini dilakukan selama 3 bulan mulai dari tahap persiapan hingga penyusunan laporan yakni mulai bulan Januari 2018 sampai bulan Maret 2018. Lokasi penelitian dilaksanakan di pabrik pala pada CV. Indospice di Tuminting Kota Manado. 


\section{Jenis dan Sumber Data}

Data yang dikumpulkan dalam penelitian ini terdiri atas dua jenis yaitu:

1. Data Primer, diperoleh melalui wawancara langsung dengan menggunakan kuisioner yang berisikan pertanyaan-pertanyaan secara tertulis pada responden untuk mendapatkan jawaban, tanggapan dan informasi yang diperlukan oleh peneliti.

2. Data Sekunder, diperoleh melalui pencatatan pada instansi atau lembaga terkait dengan penelitian ini serta literatur yang menunjang dan memiliki hubungan dengan penelitian ini.

\section{Metode Pengumpulan Data}

Data yang diambil dengan menggunakan teknik wawancara langsung kepada manajer $\mathrm{CV}$. Indospice dengan menggunakan daftar pertanyaan yang telah dipersiapkan terlebih dahulu.

\section{Konsep Pengukuran Variabel}

Variabel-variabel yang diukur dalam penelitian ini adalah sebagai berikut:

1. Produksi yaitu jumlah produksi biji pala dalam satu bulan, produksidihitung dalam satuan $\mathrm{kg}$.

2. Harga yang merupakan harga jual dari produksi pala yang dihasilkan dihitung dalam satuan rupiah per $\mathrm{kg}$.

3. Biaya produksi yaitu besarnya biaya yang dikeluarkan dalam proses produksi biji pala setiap bulan terdiri dari:

a. Biaya Tetap

1) Biaya Penyusutan Mesin

Rumus yang digunakan adalah:

Biaya Penyusutan $=\frac{\text { HargaPembelian }- \text { NilaiSisa }}{\text { UmurEkonomis }}$

2) Biaya Listrik

3) Wi-fi

4) Biaya Pulsa

5) Biaya Pemeriksaan Fitosanitari

b. Biaya Variabel

1) Biaya Tenaga Kerja

2) Biaya Bahan Baku

3) Biaya Transportasi

4) Biaya Pengemasan
4. Penerimaan yaitu perkalian antara produksi yang diperoleh dengan harga jual yang dinyatakan dalam rupiah (Rp).

5. Keuntungan yaitu nilai yang diperoleh dari hasil penjualan dikurangi dengan biaya yang dikeluarkan yang dinyatakan dalam rupiah $(\mathrm{Rp})$.

\section{Analisis Data}

Data yang dikumpulkan dalam penelitian disajikan dalam bentuk deskriptif ini kemudian dianalisis dengan menggunakan analisis keuntungan yaitu dengan menghitung selisih antara penerimaan dengan biaya yang digunakan.Dilanjutkan dengan rumus Analisis Revenue Cost Ratio (R/C) digunakan rumus sebagai berikut:

$$
\pi=\mathrm{TR}-\mathrm{TC}
$$

Dimana:

$$
\begin{array}{ll}
\pi \text { (Profit) } & \text { : Keuntungan } \\
\text { TR (Total Revenue) } & : \text { Total Penerimaan } \\
\text { TC }(\text { Total Cost }) & : \text { Total Biaya } \\
& \text { TR }=\mathrm{Q} \times \mathrm{P}
\end{array}
$$

Dimana:

TR (Total Revenue) : Total Penerimaan

Q (Quantity) : Jumlah Produksi

$\mathrm{P}$ (Price) : Harga

$$
\mathrm{TC}=\mathrm{FC}+\mathrm{VC}
$$

Dimana:

TC (Total Revenue) : Total Biaya

FC (Fixed Cost) : Biaya Tetap

VC (Variabel Cost) : Biaya Variabel

Kemudian untuk mengetahui apakah CV. Indospice menguntungkan atau tidak, dapat digunakan dengan rumus:

$$
\begin{gathered}
a=R / C \\
a=(\mathrm{P} \times \mathrm{Q}) /(\mathrm{FC}+\mathrm{VC})
\end{gathered}
$$

Dimana:

a $\quad$ : Revenue Cost Ratio
$\mathrm{R} \quad$ : Revenue / Penerimaan
$\mathrm{C} \quad$ : Cost / Biaya
$\mathrm{P} \quad$ : Output Price / Harga Produksi
$\mathrm{Q} \quad$ : Output / Jumlah Produksi
$\mathrm{FC} \quad$ : Fixed Cost / Biaya Tetap
Apabila:
$\mathrm{R} / \mathrm{C}<1$, berarti usaha pala mengalami kerugian
$\mathrm{R} / \mathrm{C}=1$, berarti usaha pala ini tidak untung atau
rugi
$\mathrm{R} / \mathrm{C} \quad>\quad 1$, berarti usaha pala mengalami
keuntungan.




\section{HASIL DAN PEMBAHASAN}

\section{Deskripsi Umum CV. Indospice}

$\mathrm{CV}$. Indospice ini berdiri pada tahun 1983 dan didirikan oleh $\mathrm{Hj}$. Bahar. CV. Indospice bergerak dalam pengolahan produk pertanian yaitu pala dan memilih biji pala sebagai bahan bakunya. Kantor CV. Indospice terletak di Jalan Tikala Ares dan gudang dari $\mathrm{CV}$. Indospice ini terletak di Jalan Islam Tuminting Kota Manado. Gudang inilah menjadi tempat pengolahan biji pala sehingga menghasilkan output biji pala utuh dan pecah. Bahan baku diperoleh dari para petani dan pengumpul yang sudah bekerja sama dengan mereka, biji pala ini sendiri dari berbagai macam daerah yaitu Siauw Ambon, Luwuk, Sitaro, Sanger, dan Minahasa. Akhir dari output yang dihasilkan akan di ekspor di beberapa negara yaitu Eropa, Belanda, Afrika Selatan, Asia dan Amerika Utara.

\section{Struktur CV. Indospice}

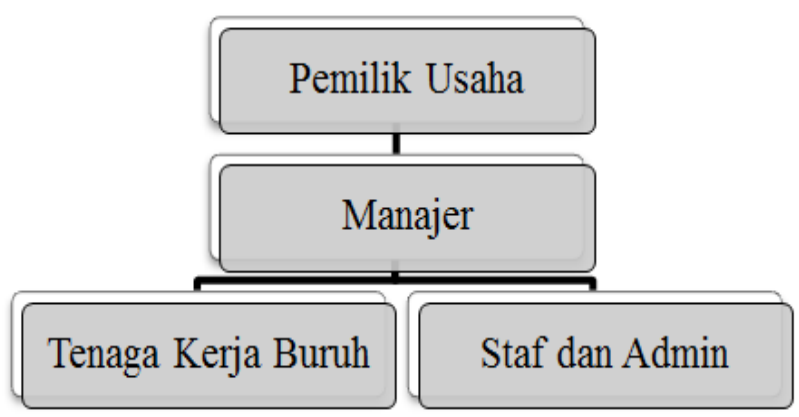

Diagram 3. Struktur Organisasi CV. Indospice

\section{Produksi}

Pada dasarnya perusahaan dalam meningkatkan produksinya bertujuan untuk meningkatkan keuntungan yang diterimanya. Produksi rata-rata biji pala yaitu sebanyak $11.640 \mathrm{~kg}$ dalam satu bulan. Produksi biji pala pecah sebanyak $8.400 \mathrm{~kg} / \mathrm{bulan}$ yang dikirim di beberapa Negara yaitu Belanda, Japan, Vietnam dan Amerika Utara sesuai dengan banyaknya permintaan dari negara tersebut. Presentasi biji pala pecah yang diekspor ke beberapa negara-negara tersebut yaitu Belanda sebesar 33\%, Japan sebesar $18 \%$, Vietnam sebesar 28\%, dan Amerika Utara sebesar $21 \%$. Produksi biji pala utuh sebanyak $3.240 \mathrm{~kg} / \mathrm{bulan}$ yang dikirim di beberapa Negara yaitu Brazil, Belanda, Afrika Selatan, dan Cina sesuai dengan permintaan setiap negara. Presentasi biji pala utuh yang diekspor ke beberapa negara yaitu Brazil sebesar 32\%, Belanda sebesar 40\%, Afrika Selatan sebesar $20 \%$ dan Cina sebesar $8 \%$. Biji pala pecah yang dihasilkan ini tidak berupa serbuk tapi berupa gilingan kasar yang berukuran kecil dari biji pala dan biji pala utuh yang dimaksud disini yaitu biji pala yang sudah terlepas dari kulit kerasnya.

\section{Harga Jual}

Harga merupakan persetujuan antara pembeli dan penjual dalam satu produk tertentu. Untuk harga biji pala per kg terbagi atas dua yaitu Rp. $90.000 / \mathrm{kg}$ untuk biji pala pecah dan Rp. 65.000/kg untuk biji pala utuh. Kedua jenis biji pala ini dijual dengan jenis grade yang sama yaitu grade $\mathrm{A}$.

\section{Biaya Tetap}

Biaya tetap adalah biaya yang tidak tergantung dari besar kecilnya volume produksi, dalam penelitian ini biaya tetap yang dihitung yaitu:

1. Biaya Pemeriksaan Fitosanitari

Biaya Pemeriksaan yaitu untuk mengetahui dan menjamin produk tersebut layak untuk dipasarkan untuk dikonsumsi karena telah lulus standar dari pemerintah untuk mendapatkan sertifikat fitosanitari.

2. Biaya Pulsa

Selama proses produksi biaya pulsa diperlukan oleh perusahaan biaya pulsa yang dimaksud disini adalah biaya pulsa untuk menghubungi pihak-pihak yang terkait dalam proses pengadaan bahan baku.

3. Biaya Wifi

Biaya wifi disini beban biaya internet yang dikeluarkan untuk menghubungkan antara produsen dan konsumen melalui jejaring sosial seperti email dan website. 


\section{Biaya Listrik}

Selama proses produksi biji pala utuh dan pecah ini juga menggunakan listrik sehingga biaya yang dikeluarkan dalam proses ini wajib dihitung dan dimasukan dalam biaya dan pada CV. Indospice memakai 23.000 watt sehingga pemakaian listrik dan biaya rata-rata pemakaian listrik adalah Rp. 8.000.000/bulan.

5. Penyusutan Mesin

Penyusutan alat merupakan biaya yang perlu dimasukan kedalam perhitungan biaya tetap. Biaya penyusutan alat (mesin) yaitu nilai penyusutan selama 1 tahun dari mesin yang digunakan, mesin yang digunakan dalam proses penggilingan biji pala. Mesin dengan berat $150 \mathrm{~kg}$ yang dapat digunakan selama 20 tahun Nilai penyusutan dihitung dengan menggunakan metode garis lurus atau straight line method:

Biaya Penyusuta $=\frac{\text { Harga Pembelian }- \text { Nilai Sisa }}{\text { Umur Ekonomis }}$

$$
=\frac{\text { Rp. } 12.025 .000-\text { Rp. } 600.000}{240 \text { bulan }}=\text { Rp. 47.604,16 }
$$

Tabel 1. Biaya Tetap Dalam Satu Bulan

\begin{tabular}{lr}
\hline Biaya Tetap & Biaya $(\mathbf{R p )}$ \\
\hline Biaya Pemeriksaan Fitosanitari & $1,500,000$ \\
Biaya Pulsa & $1,000,000$ \\
Biaya Wifi & 500,000 \\
Biaya Listrik & $8,000,000$ \\
Penyusutan Mesin & 47,604 \\
\hline Total Biaya & $11,047,604$ \\
\hline
\end{tabular}

\section{Biaya Variabel}

Dalam biaya variabel adalah biaya bahan baku, biaya tenaga kerja, biaya transportasi, dan biaya pengemasan. Berikut ini rincian biaya variabel yang dikeluarkan oleh CV. Indospice.

1. Biaya Bahan Baku

Petani dan pengumpul sebagai mitra

CV. Indospice membawa biji pala dalam sebulan sebanyak 12 kali yang setiap kalinya sejumlah 50 karung yang beratnya $20 \mathrm{~kg} / \mathrm{karung}$ dengan harga beli pada petani sebesar Rp. $41.000 / \mathrm{kg}$ baik itu biji pala utuh atau pecah.

\section{Biaya Tenaga Kerja}

Tenaga kerja pada CV. Indospice berjumlah 101 orang yang terdiri dari staf kontrak sebanyak 11 orang dan buruh lepas sebanyak 90 orang. Untuk pembagian upah staf kontrak mendapatkan upah sebesar Rp.2.800.000/bulan sedangkan untuk pembagian upah tenaga kerja buruh lepas terbagi berdasarkan jenis kelamin yakni, laki-laki mendapat upah sebesar $\mathrm{Rp}$. 85.000/hari dan perempuan sebesar Rp. $60.000 /$ hari. Setiap tenaga kerja buruh lepas memiliki target 250 biji pala yang harus dicapai dalam proses produksi untuk mendapatkan tambahan upah berupa beras sebanyak $3,5 \mathrm{~kg} /$ minggu per orang.

3. Biaya Pengemasan

Biji pala yang akan dipasarkan di packing dalam bentuk karung besar dengan total 600 karung biji pala pecah dan utuh.

\section{Biaya Transportasi}

Biaya yang dikeluarkan pada saat pengiriman barang dari gedung $\mathrm{CV}$. Indospice menuju ke pelabuhan Bitung menggunakan truk yang bermuatan maksimal 12 ton dengan jumlah biaya $\mathrm{Rp}$. 500.000/bulan.

\section{Tabel 2. Biaya Variabel Dalam Satu Bulan}

\begin{tabular}{lr}
\hline Biaya Variabel & Biaya (Rp) \\
\hline Biaya Bahan Baku & $492,000,000$ \\
Biaya Tenaga Kerja & $242,284,000$ \\
Biaya Pengemasan & $2,550,000$ \\
Biaya Transportasi & 500,000 \\
\hline Total Biaya Variabel & $737,334,000$ \\
\hline
\end{tabular}

Tabel 3. Total Biaya Dalam Satu Bulan

\begin{tabular}{lr}
\hline Biaya & Besar Biaya \\
\hline Biaya Tetap (FC) & $11,047,604$ \\
Biaya Variabel (VC) & $737,334,000$ \\
\hline Total Biaya & $748,381,604$ \\
\hline
\end{tabular}

\begin{tabular}{cccr}
\multicolumn{4}{c}{ Tabel 4. Penerimaan Dalam Satu Bulan } \\
\hline Nama Produksi & $\begin{array}{c}\text { Harga Jual } \\
\text { (Rp/Kg) }\end{array}$ & Produksi (Kg) & Penerimaan (Rp) \\
\hline Pecah & 90,000 & 8,400 & $756,000,000$ \\
Utuh & 65,000 & 3,240 & $210,600,000$ \\
\hline Total Penerimaan & & & $966,600,000$ \\
\hline
\end{tabular}




\section{Penerimaan}

Penerimaan adalah jumlah produksi dikali dengan harga jual yang berlaku. Dalam kegiatan usaha, perusahaaan selalu meningkatkan produksi dengan harapan bahwa pendapatan yang diterima akan naik sejalan dengan bertambahnya produksi yang dihasilkan.

\section{Keuntungan}

Keuntungan yang diperoleh sangat tergantung dari jumlah penerimaan yang diterima dikurangi dengan biaya yang dikeluarkan, besarnya penerimaan yang didapat merupakan hasil perkalian antara harga jual produk dengan jumlah produksi yang dihasilkan sehingga semakin tinggi produksi dengan biaya semakin kecil dan harga akan mempengaruhi keuntungan.

\section{Tabel 5. Keuntungan Dalam Satu Bulan}

\begin{tabular}{ll}
\hline Penerimaan $(\mathbf{R p})$ & $\mathbf{9 6 6 , 6 0 0 , 0 0 0}$ \\
\hline Total Biaya $(\mathrm{Rp})$ & $748,381,604$ \\
\hline Keuntungan $(\mathrm{Rp})$ & $218,218,396$ \\
\hline
\end{tabular}

\section{Analisis Revenue Cost Ratio}

Tingkat keuntungan ekonomi dapat diketahui dengan menggunakan Analisi Revenue Cost Ratio ( $\mathrm{R} / \mathrm{C}$ ratio) adalah perbandingan antara penerimaan dan biaya, ratio yang yang menjadi parameternya adalah nilai $\mathrm{R} / \mathrm{C}=1$ berarti usaha tidak untung dan tidak rugi, nilai $\mathrm{R} / \mathrm{C}<1$ berarti usaha rugi, nilai $\mathrm{R} / \mathrm{C}>1$ berarti usaha untung. Nilai $\mathrm{R} / \mathrm{C}$ $\mathrm{CV}$. Indospice sebesar 1,29 artinya untung, pada Tabel 6 berikut ini akan dijelaskan rincian data.

\section{KESIMPULAN DAN SARAN}

\section{Kesimpulan}

Penelitian ini dapat disimpulkan bahwa CV. Indospice di Tuminting Kota Manado ini mendapatkan keuntungan sebesar Rp. 218.218.396 per bulan. dan jika menggunakan $\mathrm{R} / \mathrm{C}$ cost revenue manjadi 1,29 yang berarti $\mathrm{CV}$. Indospice ini untung.

\section{Saran}

Berkaitan dengan hasil penelitian ini maka penulis memberikan saran industri yang bergerak pada penggunaan bahan baku dari komoditi pertanian yang dikenal sebagai agroindustri menjadi salah satu peluang usaha yang menawarkan keuntungan besar bagi para pelakunya. Salah satunya yang terjadi diCV. Indospice Kota Manado. Hasil penelitian inidapat menjadi contoh kondisi agroindustri yang memanfaatkan sumberdaya alam yang tersedia di Sulawesi Utara yaitu pala sebagai bahan bakunya, sehingga diharapkan lebih banyak masyarakat yang berminat terjun dalam usaha agroindustri menggunakan contoh analisis usaha dari penelitian ini. Dan diharapkan menjadi bahan pertimbangan bagi instansi-instansi terkait untuk mengembangkan usaha ini menjadi lebih baik, agar dapat memberikan dampak positif bagi Indonesia khususnya kota Manado sebagai salah satu eksportir pala terbesar di dunia.

\section{DAFTAR PUSTAKA}

Agus dan Martini. 2015. Pedoman Budidaya Pala. Balai Penelitian Tanaman Rempah dan Obat (Balittro) Bekerja sama dengan AGFOR SULAWESI.

Anoraga. 2000. Manajemen Bisnis. Jakarta: PT. Rineka Cipta.

Handoko, T.Hani. 2000. Dasar-dasar Manajemen Produksi dan Operasi. Penerbit BPFE. Yogyakarta

Kusnadar. 2010. Kimia Pangan Komponen Makro. Penerbit Dian Rakyat. Jakarta

Priyarsono. 2005. Pembangunan Pertanian. Jakarta: Gramedia Pustaka Utama.

Rahim, A. dan Hastuti, D.R.D. 2008. Ekonomika Pertanian (Pengantar, Teori, dan Kasus). Penebar Swadaya. Jakarta. 
Soekartawi. 1995. Analisis Usahatani. UT. Supriyono, R.A. 2000. Akutansi Biaya: Press. Jakarta. Perencanaan dan Pengendalian Biaya

Sukirno, Sadono. 2002. Teori Mikro Ekonomi. Cetakan Keempat Belas. Rajawali Press: Jakarta. Serta Pembuatan Keputusan, Edisi Kedua, BPFE. Yogyakarta

Supriyono, R.A. 2001. Akuntansi Biaya dan Penentuan Harga Pokok Produksi. Buku Satu, Edisi Kedua. BPFE. Yogyakarta 